\title{
Exclusive Characteristics and Management, Status and Performance Parameters of Balochi Sheep
}

\author{
Mudassar Jehan ${ }^{1}$, Masroor Ahmed Bajwa ${ }^{2}$, Mohammad Masood Tarid ${ }^{2}$, Asim Faraz ${ }^{3}$, Ecevit \\ Eyduran $^{4}$, Majed Rafeed $^{2}$, Abdul Waheed ${ }^{3}$, Muhammad Zahid Mustafa ${ }^{2}$, Jameel Ahmad, \\ Muhammad Ali ${ }^{2}$
}

${ }^{1}$ Livestock and Dairy Development Department Balochistan, Quetta, Pakistan; ${ }^{2}$ Center for Advanced studies in Vaccinology and Biotechnology (CASVAB), University of Balochistan, Quetta, Pakistan; ${ }^{3}$ Department of Livestock and Poultry Production, Bahauddin Zakariya University, Multan, Pakistan; ${ }^{4}$ Faculty of Economics and Administrative Sciences, Department of Business Administration, I $\check{g} d \imath$ University, I $\check{g} d \imath r$, Turkey.

\begin{abstract}
The current study was conducted to know about the management practices, production system, and parameters of Balochi sheep. This sheep is highly adaptive to agro-climatic conditions of Balochistan. Data of Balochi sheep ( $n=7049)$ from fifteen villages of three districts were collected regarding nutrition, administration practices, physical condition, and productive concert through performa and individual perceptions. Body weight and biometric measurements were recorded regularly for rams $(n=680)$ and ewes $(n=840)$ from three districts namely Kalat, Mastung, Quetta and from Multi-Purpose Sheep Research Station Yetabad, Loralai (MSRSYL). Sexual dimorphism is evident for several traits like it has significant effect $(\mathrm{p}<0.05)$ on weight, body length, heart girth, wither height while tail length was found to be non-significantly different between sexes ( $p>0.05)$. Balochi sheep husbandry is favorite because of its adaptability, great survival rate and growth performance, however returns from sheep production are marginal and low-cost production is still a challenge.
\end{abstract}

Keywords | Management, Performance, Balochi Sheep, Biometric Measurement, Pakistan

Received | September 24, 2020; Accepted | September 30, 2020; Published | March 15, 2021

*Correspondence | Asim Faraz, Department of Livestock and Poultry Production, Bahauddin Zakariya University, Multan, Pakistan; Email: drasimfaraz@bzu. edu.pk

Citation | Jehan M, Bajwa MA, Tariq MM, Faraz A, Eyduran E, Rafeeq M, Waheed A, Mustafa MZ, Ahmad J, Ali M (2021). Exclusive characteristics and management, status and performance parameters of balochi sheep. Adv. Anim. Vet. Sci. 9(5): 669-673.

DOI | http://dx.doi.org/10.17582/journal.aavs/2021/9.5.669.673

ISSN (Online) | 2307-8316; ISSN (Print) | 2309-3331

Copyright (C) 2021 Faraz et al. This is an open access article distributed under the Creative Commons Attribution License, which permits unrestricted use, distribution, and reproduction in any medium, provided the original work is properly cited.

\section{INTRODUCTION}

$\mathrm{T}$ here are 31 sheep breeds with an approximate population of 31.2 million in Pakistan (GOP, 2019-20; Isani and Baloch, 1996). From 1996-2018 the growth percentage of sheep was 0.20 in Pakistan while $0.22 \%$ increase was found in Balochistan (GOP, 2017-18). Increased sheep population shows farmer's interest in sheep farming in Balochistan (Kakar and Ahmad, 2004). Sheep breeds present in Balochistan are Balochi, Beverigh, Harnai and Rakhshani. Variations in growth performance are existed among sheep breeds and in different production systems (Rafik et al., 2009). System of production characterized by seasonal and cyclic migration developed in Balochistan which mainly depends on grazing. Different season has different kind of pasture, but the nutrient requirements of sheep cannot be met during winter season (Tariq et al., 2011). Production system that provides optimal production performance results is semi-intensive but the production cost is higher (Bela and Aynalem, 2009).

Balochi sheep has fat tail and is best adapted to largest area of unpleasant and difficult environmental condition in Balochistan (Jahan et al., 2012). Hereditary likelihood of specific class of sheep depends on availability of food and environmental conditions that largely affect the reproductive and productive profitability of animal (Kochapakdee et al., 1994). Different body measurements play a key role 
for the assessment of production performance (Eyduran et al., 2009; Farhat et al., 2019). Body height, length and girth of animal also have significant influence as a combined outcome of hereditary and environmental factors (Rafeeq et al., 2010). It is unfortunate that farmers are eager to keep large number of animals irrespective of their productivity, not identifying genetic potential and opting proper breeding plans. Little importance has been given to study the hereditary and point of production assessment of sheep in Balochistan. For this reason, endeavor of this research is set up the characteristics regarding the morphological and performance traits of Balochi sheep.

\section{MATERIAL AND METHODS}

\section{Base Line Study}

The present study was conducted for nine months (March - November, 2018) in the Balochi sheep $(n=7049)$ populated areas in $(n=3)$ districts of Balochistan province (Quetta, Mastung, Kalat, and ( $\mathrm{n}=15)$ villages were visited for base line study. For this purpose, different questionnaires were designed to record the scientific data for the proposed project. Comprehensive information relating to habitat, status, norms, morphological characteristics, feeding, breeding, production and management system, creation execution, wellbeing rehearses utility examples and compels of Balochi sheep raising in the local were gathered on (execution) survey explicitly intended for this reason. Need was given to Balochi sheep raising zone of the chose areas to watch the impact of crossbreeding and know presence of indigenous varieties in every territory. Families were randomly chosen, optional information on populace measurements were acquired from area domesticated animals' workplaces. Factors included during the current examination are summed up as follows:

\section{Qualitative (Morphological) Characteristics}

Sex, coat shading design, coat type, horn shape and direction, head profile, ear type of the creatures were recorded.

\section{Quantitative (Physiological) Characteristics}

Body weight and measurements (body length, heart girth, wither height and tail length) of animals, present at villages were taken randomly, information about wool and milk production was recorded.

Data of male $(n=170)$ and female $(n=210)$ from respective area (Quetta, Mastung, Kalat of Field Farm and Multi-Purpose Sheep Research Station Yetabad, Loralai (MSRSYL) were recorded. The animals were weighed by sheep weighing balance $( \pm 500 \mathrm{gm})$. The biometry measurements were taken through the sheep measuring scale $( \pm 1 \mathrm{~cm})$. Pedigree records and performance data maintained at MSRSYL under semi-intensive conditions during 2015-2018 was documented starting birth to maturity. In the present study statistics of mature sheep were utilized. The data collected was summarized using MS-excel and analyzed using $\mathrm{t}$-test in SPSS software (SPSS, 2008).

\section{RESULTS AND DISCUSSION}

Data collected of Balochi sheep breed ( $\mathrm{n}=7049)$ from villages $(n=45)$ of three districts namely Quetta, Mastung and Kalat (Table 1). These zones are known as Balochi sheep habitat and significant number of Balochi sheep is present in these districts. In Kalat and Mastung areas the estimated range from five to one hundred and fifty and a normal of the run measure was thirty animals. Kalat district (Kalat division) is main hub of this sheep. Because of its performance, adaptability, physique and white fleece coat, farmers prefer to raise this breed. Balochi sheep are kept by the Baloch clans that are not financially sound and are unaware about modern farming system. In the studied families, the normal family estimate was seven. Larger part of the livestock farmers keep them in the open zone while a few farmers keep their animals in shed during night. Sheep are kept for the most part on grazing with infrequent supplementation.

Table 1: Data of three districts of Balochi Sheep Habitat

\begin{tabular}{|lllll|}
\hline District & $\begin{array}{l}\text { No. of } \\
\text { villages }\end{array}$ & Male & Female & Observations \\
\hline Quetta & 15 & 429 & 838 & 1267 \\
\hline Mastung & 15 & 770 & 2040 & 2810 \\
\hline Kalat & 15 & 1065 & 1907 & 2972 \\
\hline Grand total & 45 & 2264 & 4785 & 7049 \\
\hline
\end{tabular}

Among 31.2 million sheep of Pakistan, Balochistan shares $48 \%$ of the aggregate sheep population. The population of Balochi sheep is approximately 4 million (GOP, 2017-18). Balochistan has a share of the very much diversified breeds of sheep, Balochi, Rakhshani, Bibrik (Beverigh), Mengali and Harnai. Most of the livestock farmers keep their animals in open areas yet some were given the sanctuary. Normally other domesticated animals like cows and goats are kept in a similar house isolated by a type of boundary. Rangelands are over grazed for most of the part observed in present study; however a few grasses are cut and sustained or put away for off season. Because of shortage of fodder in winter; grain, corn, grass, wheat straw and few supplements for sustainability are given to sheep. Two factors have caused rangeland degradation: excessive population growth and external social and economic forces (Tariq et al., 2011). Farmer wanted Balochi ewe with best apparent rams of higher genetic potential of the same breed. The farmer of Balochi regions doesn't permit this breed to mate with other on the grounds that they are less profitable than Balochi sheep. The financial situation of livestock farmers is not up to the mark because of lack of incomparable or 
Table 2: Lives body weight and biometric parameters of Balochi sheep male $(n=170)$ and female $(n=210)$ from each three districts and MSRSYL of Balochistan

\begin{tabular}{llllll} 
Location & Weight $(\mathbf{k g})$ & Body length $\mathbf{( c m})$ & Heart girth $\mathbf{( c m})$ & Wither height $(\mathbf{c m})$ & Tail length $(\mathbf{c m})$ \\
Quetta & $33.94 \pm 0.23^{\mathrm{d}}$ & $78.69 \pm 0.29^{\mathrm{d}}$ & $77.38 \pm 0.43^{\mathrm{d}}$ & $69.43 \pm 0.50^{\mathrm{d}}$ & $28.49 \pm 0.25$ \\
\hline Kalat & $37.16 \pm 0.48^{\mathrm{c}}$ & $82.01 \pm 0.40^{\mathrm{c}}$ & $81.45 \pm 0.40^{\mathrm{c}}$ & $72.02 \pm 0.38^{\mathrm{ab}}$ & $28.59 \pm 0.30$ \\
Mastung & $35.54 \pm 0.39^{\mathrm{b}}$ & $80.75 \pm 0.39^{\mathrm{b}}$ & $79.98 \pm 0.43^{\mathrm{b}}$ & $71.43 \pm 0.45^{\text {ab }}$ & $28.29 \pm 0.31$ \\
MSRSYL & $39.08 \pm 0.52^{\mathrm{a}}$ & $85.10 \pm 0.37^{\mathrm{a}}$ & $83.21 \pm 0.48^{\mathrm{a}}$ & $74.56 \pm 0.49^{\mathrm{a}}$ & $28.18 \pm 0,31$
\end{tabular}

Table 3: The effect of sex on biometric measurements of Balochi sheep (Male $n=680$ ) and (Female $n=840$ )

$\begin{array}{llll}\text { Variable } & \text { Sex } & \text { Mean } \pm \text { SE } & \text { p-value } \\ \text { Weight } & \text { Male } & 36.43 \pm 0.22 & 0.00 \\ \text { Body length } & \text { Female } & 34.28 \pm 0.19 & \\ & \text { Male } & 81.63 \pm 0.20 & 0.00 \\ \text { Heart girth } & \text { Female } & 77.04 \pm 0.23 & \\ & \text { Male } & 80.50 \pm 0.23 & 0.00 \\ \text { Wither height } & \text { Female } & 76.84 \pm 0.20 & \\ \text { Tail length } & \text { Male } & 71.86 \pm 0.24 & 0.00 \\ & \text { Female } & 70.53 \pm 0.21 & \\ & \text { Male } & 28.38 \pm 0.15 & 0.7\end{array}$

Table 4: Bivariate Correlation of Bio-metric Characteristics of Balochi sheep

$\begin{array}{lllll} & \text { Body length } & \text { Heart girth } & \text { Wither height } & \text { Tail length } \\ \text { Body weight } & .227^{* *} & .175^{* *} & .068^{* * *} & -.016 \\ \text { Body length } & .358^{* *} & .174^{* * *} & .054^{*} \\ \text { Heart girth } & & .160^{* *} & -.015 \\ \text { Wither height } & & .024 \\ \text { Tail length } & & \\ { }^{*} \text { Correlation is significant at the } 0.05 \text { level. }{ }^{*} \text {. Correlation is significant at the } 0.01 \text { level } & \end{array}$

unexploited quality of genetic pool of their animals, which causes to reduce profitability of the herds (Khan et al., 2007; Tariq et al., 2013).

\section{Physical Appearance}

Balochi sheep display black and white with black marks on the legs and head. Their face color is generally black. They are generally polled animals; having firm body with standard stature, pendulous belly, and fat tail. They have medium face with Roman nose and ears are normally medium in size. The fleece is white and coarse (Khan and Isani, 1994).

\section{Reproductive Performance}

Breeding of Balochi sheep is by characteristic mating. For the most part, one reproducing male is held per group. Anyway, in some of huge size rushes, more than one male is saved for rearing purposes (one smash for 25 ewes). Normal age at sexual development is $12-16$ months for the males and females. Normal age from the outset lambing was 19 to 25 months and lambing span is of one year. By and large, conveys 6-9 sheep in her life expectancy. Practically com- parative outcome was additionally revealed by Acharya (1982). For the most part ranchers reared the animals in October to November and lambing occurred in February to March. During these months most noteworthy quantities of births were recorded. In the current investigation, the twinning proportion esteems were estimated as 3.20\%. Whereas, Tariq et al. (2011) reported the twinning ratio values for experimental station and field farmer of Mengali sheep as $5.25 \%$ and $3.55 \%$ respectively. By and large, the reproducing male kept up per perseverance, one ram for forty ewes. During current study twin rates for MSRSYL found to be $6 \%$.

\section{Health Management}

The larger part of ranchers doesn't inoculate their sheep against infections, generally due to lack of awareness. Parasitic infestation, enterotoxaemia and pneumonia were accounted for as real infections in the zone. Sheep mortality, with a normal 5\% (extended 8-12\%) was observed as the significant medical issue. Pneumonia is accounted for the primary cause behind sheep mortality in winter season and 
enterotoxaemia in different seasons. Premature births were accounted for $1-5 \%$ of cases in November and December.

\section{UTILITY}

Balochi sheep are kept for lamb, milk and fleece production. Sheep fill in as a source of salary, run the job and as a business. Sheep are prevalently butchered amid celebrations and religious events particularly Eid-ul-Azha. Livestock farmers utilize fleece to make hand-netted cover, carpets as well as sold in marketplace for high-quality and price. In customary framework Balochistan Landi (dried meat) is set up for utilization of meat during winter season. It is likewise that one of the methods for safeguarding meat, though, other food Items like curd, lassi are utilized for their own utilization and spread food, ghee, and Kurt (dry cheddar) are sold in the neighborhood. In this regard, comparable conclusion is reported by Tariq et al. (2011).

\section{BIOMETRIC PERFORMANCE}

The results shows that location had significant effect $(\mathrm{P}<0.05)$ on body weight, body length, wither height, heart girth and tail length (Table 2). Gender had significant effect $(\mathrm{p}<0.05)$ on growth performance. Male had higher height at wither, girth and length compared to female $(\mathrm{P}<0.05)$, whereas no significant difference was found in tail length (Table 3).

The results of five breeds in diverse part of Balochistan showed significant $(\mathrm{P}<0.05)$ differences for withers height, body length and heart girth (Rafeeq et al., 2010). Pearson correlation coefficients among all biometrical characteristics obtained for Balochi sheep are given in Table-4 showing very strong correlations between the biometrical traits $(\mathrm{P}<0.01)$ and their respective correlation coefficients are statistically significant.

It was revealed that, keeping sheep under the semi-intensive conditions adapted by the farmers demonstrated to be slightly higher in cost. Gender also plays an important role in the shape and weight of the sheep (Table 3). These conclusions are in agreement with those revealed by some different researchers (Rafeeq et al., 2010; Tariq et al., 2011; Bhatt et al., 2018; Farhat et al., 2019).

Results of biometric characteristics of this study affirmed the findings of Tariq et al. (2011) who studied the information on biometry, profitable performance and survival of pure animals Mengali sheep. They set up that male sheep were heavier in weight and higher biometry parameters (body length, tallness, chest boundary) when contrasted with female ones. Rafeeq et al. (2010) evaluated the beneficial exhibition of the five kinds of sheep types of Balochistan territory and found it to be basically unique sheep with critical extraordinary $(\mathrm{P}<0.05)$ charac- teristics for wilts, stature, body length and chest circumference. Predictable development execution was found in Balochi contrasted and various varieties. They concurred that inherited capability of breeds and natural factors may improve decent varieties in gainful and biometric execution. Specialists likewise revealed that chest bigness is the best prescient condition for body weight in caught Stone's sheep (Singh et al., 2014) and comparable outcomes were accounted by Abdelhady et al. (2018).

\section{CONCLUSION}

The results of the study revealed that Balochi breed is a distinctive sheep having unique qualities and characteristic features. Animals kept under the semi-intensive conditions adapted by the farmers demonstrated to be slightly higher in cost. It was also observed that Balochi sheep farming is preferred because of its adaptability, great survival rate and growth performance. There should be more studies pertaining to different management systems regarding sheep production for a deep look into sheep husbandry.

\section{ACKNOWLEDGEMENTS}

The help extended by the sheep herders and the kind support of management of Multi-Purpose Sheep Research Station Yetabad, Loralai is gratefully acknowledged.

\section{CONFLICT OF INTEREST}

There is no conflict of interest.

\section{AUTHORS CONTRIBUTION}

All authors contributed to make this manuscript possible. Mudassar Jehan conducted research. Masroor Ahmed Bajwa supervised the research. Mohammad Masood Tariq helped in research completion. Ecevit Eyduran and Abdul Waheed helped in analysis. Asim Faraz, Muhammad Zahid Mustafa and Jameel Ahmad helped in write-up. Majed Rafeeq and Muhammad Ali reviewed the paper.

\section{REFERENCES}

-Abdelhady A, Hassanenin AE, Fahmy A (2018). Sheep identity recognition, age and weight estimation datasets. arXiv:1806:04017.www.egyptscience.net

-Acharya, RM (1982). Sheep and goat breeds of India. FAO Animal Production And Health Paper 30, FAO, Rome. http://www.fao.org/3/X6532E/X6532E04.htm

- Bela B, Aynalem H (2009). Factors affecting growth performance of sheep under village management conditions in southwestern part of Ethiopia. Livest. Res. Rural Develop. 21: 11 .

-Bhatt C, Hassanien A, Shah NA, Thik J (2018). Barqi Breed 
Sheep Weight Estimation based on Neural Network with Regression. arxiv:1807-10568.

- Eyduran E, Karakus K, Karakus S, Cengiz F (2009). Usage of factor scores for determining relationship among body weight and somebody measurements. Bulgarian J. Agri. Sci. 15: 373 - 377 .

- Farhat I, Tariq MM, Ecevit E, Zil-e-Huma (2019). Fitting Nonlinear Growth Models on weight in Mengali sheep through Bayesian inference read. Pakistan J. Zool. 51: 459 - 466. https://doi.org/10.17582/journal. pjz/2019.51.2.459.466

- GOP (2017-2018). Economic Survey of Pakistan, Economic Advisory Wing Islamabad, Pakistan.

- GOP (2019-2020). Economic Survey of Pakistan, Economic Advisory Wing Islamabad, Pakistan.

-Isani GB, Baloch MN (1996). Sheep and goat breed in Pakistan. Press Corporation, Karachi.

-Jahan M, Tariq MM, Kakar MA, Waheed A (2012). Reproductive performance of Balochi sheep in different ecological zones of Balochistan, Pakistan. Pakistan Vet. J. 20: 30 - 33.

-Khan BB, Isani GB (1994). Breeds and types of livestock in Pakistan. Animal Husbandry (Book) published by National Book Foundation.

- Kakar MA, Ahmad M (2004). An over-view of livestock in Balochistan (2003-2004). Livestock and Dairy Development Department Balochistan, Quetta. 40 - 85.

-Khan SM, Khan MA, Ahmad S, Mahmood S (2007). Genetic resources and diversity in Pakistani sheep. Int. J. Agri. Biol. 9: 941 - 944.

-Kochapakdee SW, Pralokarn S, Laapetrchara AS, Norto BW (1994). Grazing management studies with Thai goats. Productivity of female goats grazing newly established pasture with varying levels of supplementary feeding. Asian Austr. J. Anim. Sci. 7: 289 - 293. https://doi.org/10.5713/ ajas.1994.289

- Rafeeq M, Tariq MM, Ahmad M (2010). Comparative study to estimate the productive performance of different sheep breeds of Balochistan in semi intensive conditions. Anim. Biol. Anim. Husb. Int. J. Bioflux Soc. 2: 35 - 38.

-Refik A, Ceyhar A, Ozder M, Sezenler J (2009). Genetic and non-genetic parameter estimates for growth traits in Turkish Marino lambs. J. Anim. Vet. Advanc. 8: 1729 - 1734.

-Singh S, Raja KN, Ganguly I, Arora R (2014). Prediction of body weights from body biometry in Koraput sheep by regression analysis. Indian Vet. J. 91: 24 - 27.

-SPSS Inc. Released (2008). SPSS Statistics for Windows, Version 17.0. Chicago: SPSS Inc. Chicago, IL. USA.

- Tariq MM, Bajwa MA, Javed K, Rafeeq M, Awan MA, Rashid N, Waheed A, Amin S, Khan MA, Bukhari FA (2013). Assesment of wool characteristics of Mengali sheep of Balochistan. J. Anim. Plant Sci. 23: 721 - 726.

-Tariq MM, Bajwa MA, Abbas F, Ecevit E (2011). Some morphological, fertility and growth traits for Mengali sheep of Balochistan, Pakistan. Iğdır Üni. Fen Bilimleri Enst. Der. Iğdır Univ. J. Inst. Sci. Tech. 1: 63 - 68. 